\title{
Socio-Demographic Factors Associated with Advanced Stage of Cervical Cancer at Diagnosis in Kenyatta National Hospital, Kenya: A Cross Sectional Study
}

Kirema Makena Frida ${ }^{1}$, Wagoro Miriam Carole Atieno ${ }^{2}$ and Michael Habtu ${ }^{3 *}$

${ }^{1}$ Clinical practice, Kenyatta National Hospital, P.O. Box 20723-00202 Nairobi, Kenya

${ }^{2}$ University of Nairobi, College of Health Sciences, School of Nursing Sciences, P.O. Box 19676-00202 Nairobi, Kenya.

${ }^{3}$ Mount Kenya University, School of Health Sciences, Department of Public Health, P.O. Box 5826, Kigali Campus, Rwanda.

\begin{abstract}
Background: Cervical cancer is the most common and leading cause of deaths due to cancer among women in Kenya. Early detection is necessary for initiation of treatments to prevent deaths. Identification of factors that contribute to advanced stage of cervical cancer is the first step towards early detection.
\end{abstract}

Objectives: To determine socio-demographic factors associated with advanced stage of cervical cancer at diagnosis in Kenyatta National Hospital.

Materials and methods:A cross-sectional study of 152 women with a histological proven cervical cancer was conducted at Kenyatta National Hospital. The women were selected using random sampling method. Information on demographic characteristics and stage of cervical cancer were abstracted retrospectively by auditing patients' records from January 2014 to June 2014. Stages I and II were classified as 'early stage' and stages III and IV as 'advanced stage'. Chi-square test $(p$-value $<0.05)$ was used to determine association between advanced stage of cervical cancer and socio-demographic characteristics. Multiple logistic regression analysis was performed to determine the independent factors associated with advanced stage of cervical cancer at diagnosis.

Results: Out of 152 patients with cervical cancer, $53.9 \%$ had advanced stage of cancer at diagnosis. Following multiple logistic regression analysis, the following factors were independently associated with advanced stage of cervical cancer: older age (50 to 75 years) $(A O R=4.25 ; 95 \% \mathrm{Cl}=1.08-16.75 ; \mathrm{P}=0.039)$, being single ( $\mathrm{AOR}=2.28$; $95 \% \mathrm{Cl}=1.03-5.06 ; \mathrm{P}=0.043$ ), never attended school ( $\mathrm{AOR}=5.91 ; 95 \% \mathrm{Cl}=1.96-17.78 ; \mathrm{P}=0.002$ ), attended primary school $(A O R=4.13 ; 95 \% \mathrm{Cl}=1.60-10.63 ; \mathrm{P}=0.003$ ) and HIV positive women (AOR=2.86; $95 \% \mathrm{Cl}=1.25-6.59$; $\mathrm{P}=0.013)$.

Conclusion:More than half of the patients presented with advanced stage of cervical cancer at diagnosis. None/low level of education, old age, being single and HIV infection were associated with advanced stage of cancer at diagnosis. Regular cervical cancer screening targeting these women could reduce advanced stage of cervical cancer at diagnosis.

Keywords: Cervical cancer; Advanced stage at diagnosis; Sociodemographic factors

Abbreviation: AIDS: Acquired Immunodeficiency Syndrome; AOR: Adjusted Odds Ratio; ASCCP: American Society for Colposcopy and Cervical Pathology; CI: Confidence Interval; FPC: Finite Population correction; FIGO: International Federation of Gynaecology and Obstetrics; HIV: Human Immunodeficiency Virus; KNH/UON: Kenyatta National Hospital/University of Nairobi; OR: Odds Ratio; SPSS: Statistical Package for Social Sciences; USA: United States of America; WHO: World Health Organization.

\section{Introduction}

In 2008 cervical cancer was, reportedly, the third most commonly diagnosed cancer in women worldwide, with an estimated 529,800 new cases annually and 300,000 deaths of which $85 \%$ occurred in developing countries [1,2]. Cervical cancer is the most curable form of any human cancer if detected at the precancerous stage [3]. However, it continues to be a major public health threat to women in many low and medium income countries where it is still the leading cancer among women [1]. Sub-Saharan Africa bears the highest global burden of this fatal yet preventable disease [4]. Eastern Africa (including Kenya) is the most affected region by cervical cancer with an age standardized incidence rate and mortality rate of 25.3 and 34.5 per 100,000 women respectively [5].
The 2012 estimates reported 4,802 new cervical cancer cases diagnosed in Kenya where it ranked as the $1^{\text {st }}$ leading cause of female cancer [6] based on crude incidence rates. Cancer of the cervix is also the most common female cancer in women aged 15 years to 44 years in Kenya [6] and accounts for an average of 2000 deaths per year [7]. Lack of cervical screening leads to advanced stage at diagnosis which consequently contributes to high mortality rates among African women [8-10]. Several studies $[11,12]$ have already indicated that advanced stage of cervical cancer at diagnosis is correlated with lower survival rates. For instance, survival rate of cervical cancer is reportedly $80 \%$ to $99 \%$ in stage I, $60 \%$ to $90 \%$ in stage II, $30 \%$ to $50 \%$ in stage III and $15 \%$ to $20 \%$ in stage IV.

${ }^{*}$ Corresponding author: Michael Habtu, Mount Kenya University, School of Health Sciences, Department of Public Health, P.O. Box 5826, Kigali Campus, Rwanda. Tel: 250784460645; Email: mikel.habtu@gmail.com

Received June 10, 2017; Accepted July 19, 2017; Published July 22, 2017

Citation: Frida KM, Atieno WMC, Habtu M (2017) Socio-Demographic Factors Associated with Advanced Stage of Cervical Cancer at Diagnosis in Kenyatta National Hospital, Kenya: A Cross Sectional StudyJ Cancer Sci Ther 9: 554-561. doi: 10.4172/1948-5956.1000473

Copyright: @ 2017 Frida KM, et al. This is an open-access article distributed under the terms of the Creative Commons Attribution License, which permits unrestricted use, distribution, and reproduction in any medium, provided the original author and source are credited. 
Literature indicates that over $80 \%$ of women with cervical cancer in developing countries are diagnosed at advanced stage [13]. For example, in Nigeria about $81 \%$ of cases are diagnosed in stages III-IV [14] while in Kenya, $62 \%$ of patients presented with cervical cancer in stages III-IV [15]. Advanced stage of cervical cancer at diagnosis results from multiple complex factors including lack of awareness and knowledge about cervical cancer, inability to establish effective followup treatment, delay of reporting abnormal results to patients, lack of equipment and inadequate trained health care providers, unaffordable treatments for cervical cancer and limited available health care services [16-20]. In a study by Murray et al. [21], many Kenyan cancer patients hid their diagnosis from family members because of the financial burdens of hospital and medication payments. Additionally, fear of alteration in their body image, sexuality, reduction in fertility, and rejection by their spouse led to avoidance of care until they developed advanced cervical cancer [22]. Many low and middle-income countries have had established cervical cancer prevention programs yet, cervical cancer screening remains very low $[23,24]$. A report by the World Health Organization (WHO) indicated that cervical cancer screening coverage in Kenya for all women 18 years to 69 years is only $3.2 \%$ [6] despite its magnitude. A previous study on knowledge and practices about cervical cancer and Pap smear testing carried out in Kenyatta National Hospital revealed that only 22\% of women had a Pap smear test [25]. Similarly, Morema et al. [26] reported that $17.5 \%$ of women aged 18 years to 49 years went for cervical screening at a regional hospital. Furthermore, a study in another Kenyan National hospital reported that only $12.5 \%$ of the participants reported being screened [27]. Some of the reasons cited for the low uptake of cervical screening include lack of awareness, perception of not being at risk, inadequate access to screening programs, perceived examination discomfort, and fear of being diagnosed with cancer [28-30]. There is also evidence that women of lower socio-economic status from different countries are less likely to participate in cancer screening [31-33]. Similarly, sociocultural barriers such as embarrassment for pelvic examination have been argued as leading factors of not using available screening services regularly [34]. Studies in Kenya have so far looked at awareness and prevention of cervical cancer and the knowledge and attitudes of women [35]. Consequently, there have been scaled-up campaigns to create awareness and promote uptake of screening services at public and private health institutions from Dispensary (Level 1) to National Referral Hospitals. Despite availability of nationwide screening services for cervical cancer, women still present with advanced stage of invasive disease. Kenya like other developing countries is a low in resource setting facing a number of similar challenges. Many women cannot afford the cost of screening. In the Kenyatta National Referral Hospital, Pap smear costs KShs 550 (Approx \$7). However, the client must pay for a file or identification card of 500 Kenyan Shillings (KShs) (Approx\$ 6.5). The client then needs to wait for the Pap results for a minimum of two weeks. At the leading private hospitals, Pap smear costs on average KShs 1200 (\$15) with a waiting time of 2 days for the pathology results. In the public hospitals, the Pap smear procedure is subsidized by the government and the client pays KShs 20 (Approx \$0.25) for registration but the waiting period is two weeks. Though some studies [36-39] have revealed socio-demographic differences in stages of cervical cancer at diagnosis, it has not been studied in Kenya. The objective of this study was therefore to establish the socio-demographic factors associated with advanced cervical cancer at diagnosis among patients presented with cervical cancer in Kenyatta National Hospital.

\section{Materials and Methods}

\section{Setting}

The study was conducted at Kenyatta National Hospital with a bed capacity of 2000. This is a National Referral Hospital, located in Nairobi, the country's capital city. It offers both preventative and curative services for a variety of illnesses to patients from all over Kenya with an average of 600,000 outpatient visits and 89,000 inpatients annually. It is the only public hospital with colposcopy clinic for patients with cervical cancer and Radiotherapy clinic for referrals from all over Kenya including advanced cervical cancer for palliative radiotherapy. The hospital receives over $70 \%$ of patients with cervical cancer from all over the country. The patients are referred to Kenyatta National Hospital for further laboratory investigations and treatment. Screening for cancer of the cervix at Kenyatta National Hospital, follows the three-step strategy recommended by the American Society for Colposcopy and Cervical Pathology (ASCCP) guidelines, which entails Papanicolaou (Pap) smear, colposcopy/biopsy and loop electrosurgical excision procedure [36]. Radiation therapy, surgery and chemotherapy remain standard treatment options for cervical cancer at Kenyatta National Hospital with radiation therapy being the first line treatment although significant numbers of patients fail to respond.

\section{Study design}

This was a cross sectional study of 152 women diagnosed with cervical cancer. A retrospective review of clinical profile (records) with confirmed diagnosis of cervical cancer based on histopathological examination during the period of $1^{\text {st }}$ January to $30^{\text {st }}$ June 2014 was carried out.

\section{Sample size} [40]

The sample size was calculated using the formula of Fishers et al.

$$
\{\mathrm{n}=\mathrm{Z} 21-\mathrm{a} \mathrm{P}(1-\mathrm{P}) / \mathrm{d} 2=(1.96) 2(0.62)(0.38) /(0.05) 2=362\}
$$

The proportion of advanced cervical cancer at diagnosis (stages IIIIV) was taken as $62 \%$ according to Sanghvi [15]. However, sample size adjustment was made since the target population was $<10,000$ (262) using finite population correction (FPC) factor formula [41].

$$
\{\mathrm{nf}=\mathrm{n} /(1+\mathrm{n} / \mathrm{N})=362 /(1+362 / 262)=152\}
$$

Therefore, the minimum sample size of the study was 152 clinical profiles with cervical cancer.

\section{Sampling technique}

All the clinical profiles regarding cervical cancer during the period of January 2014 to June 2014 representing 6 months were selected from the cancer registry of the hospital. Assigned numbers for the clinical profiles were entered into Statistical Package for Social Sciences (SPSS) and the required sample size (58.5\% of the total) were selected randomly using SPSS software.

\section{Data collection}

Data was collected using a structured checklist which was designed to extract information from the clinical profiles. Information on sociodemographic characteristics of participants and stages of cervical cancer at diagnosis were extracted. The stage of cervical cancer at diagnosis was defined according to International Federation of Gynaecology and Obstetrics (FIGO) [42] system of gynaecological cancer staging. According to the FIGO, cervical cancer is clinically staged as follows: stage I, confined to the cervix; stage II, extending beyond the cervix, but not into the pelvic wall, involving two-thirds of the upper vagina; stage III, extending into the pelvic wall and involving the lower third of the vagina but not adjacent organs; and stage IV, extending beyond the pelvis into adjacent and distant organs. 
At Kenyatta National Hospital cervical cancer diagnosis and staging is done by at least two gynaecologist based on the FIGO criteria and based on pathologist's histopathological examination report. In this study, stages I and II at diagnosis were categorized as early stage while stages III and IV were advanced stage in accordance with FIGO criteria.

\section{Data analysis}

Data extracted in structured checklist was double entered into a computer database using MS access application. Regular file backup was done to avoid any data loss or tampering. Data cleaning and validation was performed on a daily basis in order to achieve a clean dataset that was exported into SPSS Version 20.0 (IBM Corporation, Armonk, NY, USA) ready for analysis. Pearson's chi-square test was used to establish the association between the dependent variable (stages of cervical cancer) and independent variables in order to determine which ones had significant association. Binary logistic regression was used to model advanced stage of cervical cancer using factors identified to be significant at $\mathrm{P}<0.05$ during bivariate analysis. Backward conditional method was specified with removal at $\mathrm{P}<0.05$.

\section{Ethical Considerations}

The study was authorized by Kenyatta National Hospital/University of Nairobi (KNH/UON) Ethics and Research Committee. Additionally, permission to extract data from the clinical profile was granted by the $\mathrm{KNH}$ record and cancer registry management.

\section{Results}

\section{Distribution of the stages and severity of cervical cancer at diagnosis}

Distribution of cervical cancer stages among respondents at diagnosis shows that $34.2 \%$ were in stage III, $30.3 \%$ in stage II, $19.7 \%$ in stage IV and $15.5 \%$ were in stage I. On categorizing stage III and IV as advanced stage and stage I and II as early stage, 53.9\% and $46.1 \%$ had advanced and early stage of cervical cancer respectively (Table 1).

\section{Socio-demographic characteristics stratified by severity of cervical cancer}

The relationship of socio-demographic characteristics in relation to advanced diagnosis of cervical cancer is presented in Table 2 . There was a significant difference between the age of the women and advanced cervical cancer at diagnosis $(\mathrm{P}=0.004)$, where older women had increased proportion of advanced cervical cancer at diagnosis than younger women. Delayed diagnosis of cervical cancer was significantly $(\mathrm{P}=0.027)$ more among single women than married women. Women's level of education was significantly associated with advanced cervical cancer at diagnosis $(\mathrm{P}=0.003)$. The advanced cervical cancer during diagnosis was significantly more among women who did not attend school and those who attended primary school than those who attended secondary and above. Women who were HIV positive were found to have significantly increased proportion of advanced cervical cancer at diagnosis compared to HIV negative women $(\mathrm{P}=0.016)$.

\section{Socio-demographic factors associated with advanced cervical cancer using unadjusted and adjusted logistic regression}

Multivariable analysis was performed in order to identify factors independently associated with advanced cervical cancer at diagnosis (Table 3). Six (6) variables with p-value $<0.05$ in the bivariate analysis were considered together in the multiple regression analysis. Upon fitting these factors using binary logistic regression and specifying 'backward conditional' method with removal at $\mathrm{P}<0.05$, four (4) factors retained in the final model (Table 3).

Women aged 50 years to 75 years were about 4 times more likely to be diagnosed with advanced cervical cancer than to those women aged 18 years to 35 years, $(A O R=4.25 ; 95 \% C I=1.08-16.75 ; P>0.05)$. Single women were found to have 2.28 -fold risk of advanced cervical cancer during diagnosis than married women $(\mathrm{AOR}=2.28$; $95 \% \mathrm{CI}=1.03-5.06$; $\mathrm{P}>0.05)$. Advanced cervical cancer was 5.91 times more likely to be

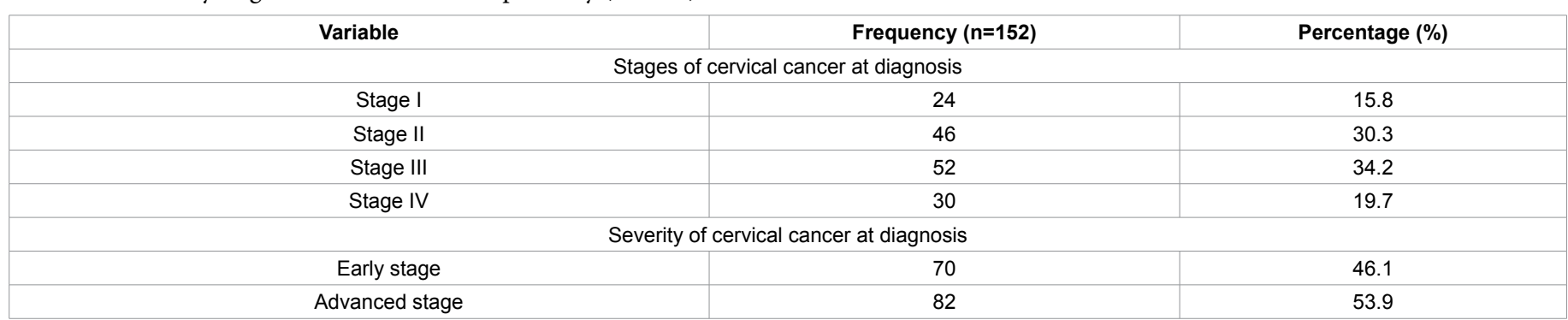

Table 1: Distribution of the stages and severity of cervical cancer at diagnosis.

\begin{tabular}{|c|c|c|c|c|}
\hline \multirow{2}{*}{ Variables } & \multirow{2}{*}{ Total, $\mathbf{n}(\%)$} & \multicolumn{2}{|c|}{ Stages of cervical cancer } & \multirow{2}{*}{$\begin{array}{c}X^{2} \text { test } \\
{ }^{*} p \text { value }\end{array}$} \\
\hline & & Advanced, n (\%) & Early, n (\%) & \\
\hline \multicolumn{5}{|c|}{ Age in years } \\
\hline 18 to 35 & $16(10.5 \%)$ & $6(7.3 \%)$ & $10(14.3 \%)$ & \multirow{3}{*}{0.004} \\
\hline 36 to 49 & $53(34.9 \%)$ & $21(25.6 \%)$ & $32(45.7 \%)$ & \\
\hline 50 to 75 & $83(54.6 \%)$ & $55(55.1 \%)$ & $28(40.0 \%)$ & \\
\hline \multicolumn{5}{|c|}{ Geographical origin } \\
\hline Central & $53(34.9 \%)$ & $27(32.9 \%)$ & $26(37.1 \%)$ & \multirow{3}{*}{0.057} \\
\hline Western & $49(32.2 \%)$ & $33(40.2 \%)$ & $16(22.9 \%)$ & \\
\hline Coast and North Eastern & $50(32.9 \%)$ & $22(26.8 \%)$ & $28(40.0 \%)$ & \\
\hline \multicolumn{5}{|c|}{ Marital status } \\
\hline Married & $83(54.6 \%)$ & $38(46.3 \%)$ & $45(64.3 \%)$ & \multirow{2}{*}{0.027} \\
\hline Single & $69(45.4 \%)$ & $44(53.7 \%)$ & $25(35.7 \%)$ & \\
\hline
\end{tabular}


Citation: Frida KM, Atieno WMC, Habtu M (2017) Socio-Demographic Factors Associated with Advanced Stage of Cervical Cancer at Diagnosis in Kenyatta National Hospital, Kenya: A Cross Sectional StudyJ Cancer Sci Ther 9: 554-561. doi: 10.4172/1948-5956.1000473

\begin{tabular}{|c|c|c|c|c|}
\hline \multicolumn{5}{|c|}{ Religion } \\
\hline Christian & $140(92.1 \%)$ & 77 (93.9\%) & $63(90.0 \%)$ & \multirow{2}{*}{0.374} \\
\hline Muslim & $12(7.9 \%)$ & $5(6.1 \%)$ & $7(10.0 \%)$ & \\
\hline \multicolumn{5}{|c|}{ Level of education } \\
\hline Never attended & $46(30.3 \%)$ & $30(36.6 \%)$ & $16(22.9 \%)$ & \multirow{3}{*}{0.003} \\
\hline Primary & $65(42.8 \%)$ & $39(47.6 \%)$ & $26(37.1 \%)$ & \\
\hline Secondary and above & $41(27.0 \%)$ & $13(15.9 \%)$ & $28(40.0 \%)$ & \\
\hline \multicolumn{5}{|c|}{ Occupation } \\
\hline Employed & $82(53.9 \%)$ & $46(56.1 \%)$ & $36(51.4 \%)$ & \multirow{2}{*}{0.565} \\
\hline Unemployed & $70(46.1 \%)$ & $36(43.9 \%)$ & $34(48.6 \%)$ & \\
\hline \multicolumn{5}{|c|}{ Parity ${ }^{a}$} \\
\hline 0 to 3 & $52(35.4 \%)$ & $22(28.2 \%)$ & $30(43.5 \%)$ & \multirow{3}{*}{0.070} \\
\hline 4 to 6 & $51(34.7 \%)$ & $27(34.6 \%)$ & $24(34.8 \%)$ & \\
\hline 7 to 12 & $44(29.9 \%)$ & $29(37.2 \%)$ & $15(21.7 \%)$ & \\
\hline \multicolumn{5}{|c|}{ History of contraceptive use ${ }^{b}$} \\
\hline Yes & $61(44.5 \%)$ & $35(46.7 \%)$ & $26(41.9 \%)$ & \multirow{2}{*}{0.579} \\
\hline No & $76(55.5 \%)$ & $40(53.3 \%)$ & $36(58.1 \%)$ & \\
\hline \multicolumn{5}{|c|}{ Diabetes } \\
\hline Yes & $7(4.6 \%)$ & $4(4.9 \%)$ & $3(4.3 \%)$ & \multirow{2}{*}{0.862} \\
\hline No & 145 (95.4\%) & $78(95.1 \%)$ & $67(95.7 \%)$ & \\
\hline \multicolumn{5}{|c|}{ HIV $^{c}$} \\
\hline Positive & $53(37.9 \%)$ & $36(46.8 \%)$ & $17(27.0 \%)$ & \multirow{2}{*}{0.016} \\
\hline Negative & $87(62.1 \%)$ & $41(53.2 \%)$ & $46(73.0 \%)$ & \\
\hline \multicolumn{5}{|c|}{ Human Papilloma Virus ${ }^{d}$} \\
\hline Yes & $9(13.2 \%)$ & $4(6.6 \%)$ & $13(10.1 \%)$ & \multirow{2}{*}{0.208} \\
\hline No & $59(86.8 \%)$ & $57(93.4 \%)$ & $116(89.9 \%)$ & \\
\hline \multicolumn{5}{|c|}{$\begin{array}{l}\text { aMissing records } 5,{ }^{b} \text { Missing records } 15,{ }^{c} \text { Missing records } 12,{ }^{d} \text { Missing records } 24 \\
\text { 'Significant at } p<0.05\end{array}$} \\
\hline
\end{tabular}

Table 2: Socio-demographic characteristic stratified by severity of cervical cancer at diagnosis.

\begin{tabular}{|c|c|c|c|c|}
\hline \multirow{2}{*}{ Variables } & \multicolumn{2}{|c|}{ Stages of cervical cancer } & \multirow{2}{*}{ COR $(95 \% \mathrm{Cl})$} & \multirow{2}{*}{ AOR $(95 \% \mathrm{Cl})$} \\
\hline & Advanced & Early & & \\
\hline \multicolumn{5}{|c|}{ Age in years } \\
\hline 18 to 35 & 6 & 10 & Reference & Reference \\
\hline 36 to 49 & 21 & 32 & $1.09(0.35-3.46)$ & $1.56(0.38-6.36)$ \\
\hline 50 to 75 & 55 & 28 & $3.27(1.08-9.93)^{\star}$ & $4.25(1.08-16.75)^{*}$ \\
\hline \multicolumn{5}{|c|}{ Geographical origin } \\
\hline Central & 27 & 26 & $1.32(0.61-2.87)$ & $1.18(0.46-3.06)$ \\
\hline Western & 33 & 16 & $2.63(1.16-5.95)^{\star}$ & $1.72(0.60-4.96)$ \\
\hline Coast and North Eastern & 22 & 28 & Reference & Reference \\
\hline \multicolumn{5}{|c|}{ Marital status } \\
\hline Married & 38 & 45 & Reference & Reference \\
\hline Single & 44 & 25 & $2.08(1.08-4.01)^{*}$ & $2.28(1.03-5.06)^{*}$ \\
\hline \multicolumn{5}{|c|}{ Religion } \\
\hline Christian & 77 & 63 & $1.71(0.52-5.65)$ & -- \\
\hline Muslim & 5 & 7 & Reference & -- \\
\hline \multicolumn{5}{|c|}{ Level of education } \\
\hline Never attended & 30 & 16 & $4.04(1.65-9.88)^{* *}$ & $5.91(1.96-17.78)^{\star \star}$ \\
\hline Primary & 39 & 26 & $3.23(1.42-7.37)^{\star \star}$ & $4.13(1.60-10.63)^{\star \star}$ \\
\hline Secondary and above & 13 & 28 & Reference & Reference \\
\hline \multicolumn{5}{|c|}{ Occupation } \\
\hline Employed & 46 & 36 & Reference & -- \\
\hline Unemployed & 36 & 34 & $0.83(0.44-1.57)$ & -- \\
\hline \multicolumn{5}{|c|}{ Parity } \\
\hline 0 to 3 & 23 & 30 & Reference & Reference \\
\hline
\end{tabular}




\begin{tabular}{|c|c|c|c|c|}
\hline 4 to 6 & 27 & 25 & $1.41(0.65-3.04)$ & $0.79(0.29-2.17)$ \\
\hline 7 to 12 & 32 & 15 & $2.78(1.23-6.31)^{*}$ & $2.12(0.66-6.75)$ \\
\hline \multicolumn{5}{|c|}{ History of contraceptive use } \\
\hline Yes & 35 & 26 & $1.21(0.62-2.39)$ & -- \\
\hline No & 40 & 36 & Reference & -- \\
\hline \multicolumn{5}{|c|}{ Diabetes } \\
\hline Yes & 4 & 3 & $1.15(0.25-5.30)$ & -- \\
\hline No & 78 & 67 & Reference & -- \\
\hline \multicolumn{5}{|c|}{ HIV } \\
\hline Positive & 36 & 17 & $2.38(1.16-4.85)^{*}$ & $2.86(1.25-6.59)^{\star}$ \\
\hline Negative & 41 & 46 & Reference & Reference \\
\hline $\begin{array}{l}\text { R: Crude Odds Ratio; } \\
0.05 ;{ }^{* *} p<0.01 \text { using }\end{array}$ & ;AOR & 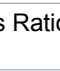 & & \\
\hline
\end{tabular}

Table 3: Adjusted and unadjusted analysis of factors associated with advanced cervical cancer.

among women who didn't attend school (AOR=5.91; 95\% CI=1.9617.78; $\mathrm{P}>0.01)$ than those attended secondary and above. Similarly, women attended primary school had about 4 times more likely to have advanced cervical cancer compared to secondary and above, (AOR=4.13; 95\% $\mathrm{CI}=1.60-10.63 ; \mathrm{P}>0.01$ ). HIV positive women were 2.86-fold more likely to be presented with advanced cervical cancer at diagnosis compared to HIV negative women $(\mathrm{AOR}=2.86$; $95 \% \mathrm{CI}=1.25$ $6.59 ; \mathrm{P}>0.05)$. After multivariable analysis, parity and geography origin were found insignificant with advanced diagnosis (Table 3 ).

\section{Discussion}

Women with the advanced stages of cervical cancer at diagnosis are less likely to survive longer. This can be prevented by regular checkup and increased coverage of cervical cancer screening programme. Cervical screening coverage in Kenya is $3.2 \%$ for all women 18 years to 69 years [6]. The focus of the cervical cancer program in Kenya is women aged 25 years to 49 years. However, women outside this age group who request or for whom screening is recommended are not denied services. The recommended screening cycle for the Kenya program is every 5 years, except for HIV positive women. All HIV positive women with history of sexual activity, and are 18 years to 65 years old are screened for cervical cancer as part of comprehensive HIV care. The screening cycle for this category is at diagnosis of HIV, after every 6 months in year one and then yearly if normal [43]. For women who screen positive for premalignant cervical lesions, a confirmatory colposcopy is required [44]. Cervical cytology, however, is not a feasible method of screening in many African countries given the required level of medical and laboratory infrastructure and trained personnel, multiple return visits with poor patient tracking strategies, and availability of such services are often limited to capital cities.

The stage of cervical cancer at the time of presentation is the single most important independent prognostic factor influencing the mortality rate $[45,46]$. The prevalence of advanced cervical cancer at diagnosis (FIGO stage III and IV) in this study was more than half (53.9\%). This was similar to the report in Morocco at 54.5\% [38] and slightly higher than in a study carried out in Tanzania at $47.3 \%$ [47].

However, the percentage is lower than what has been reported by other studies in Sub-Saharan Africa involving general cervical cancer patients which have reported more than $70 \%[48,49]$. Similar studies conducted in Sudan [50] and Nigeria [51] reported that up to $72 \%$ and $86 \%$ respectively of the women with cervical cancer were diagnosed at an advanced stage (FIGO stage III and IV). Our study findings were also lower than the Nepal and Iran studies that reported study that reported
80.9\% [52] and 89.1\% [53] respectively. According to Mlange et al. [54], these differences could be explained by geographical variability and social economic status which could hinder the accessibility to health care facilities and probably poor health seeking behaviour. Our findings showed that majority of women with advanced stage were from Western Kenya region but this was not significant in the multivariable analysis.

In this study patients had a higher probability of being diagnosed with advanced stage of cervical cancer if they had a lower degree of education. Similar relationship between education and advanced diagnosis of cervical cancer has been reported in some countries including United States of America (USA), Florida [55], South India [56], Sudan [50], Nepal [52] and Morocco [38]. It is found that women with less education have difficulties in understanding the benefits of screening [57] and the health-seeking behaviour of many of the women is guided by traditional notions of ill health; many of them are not sure about the healing provided by modern medicine [58]. Moreover, degree of education is indirectly linked with the average income and understanding of nature of the disease [59-61], which in turn increases the risk of advanced stage of cervical cancer.

Older age (50 years to 75 years) was associated with increased odds of diagnosis at an advanced stage $(\mathrm{AOR}=4.25 ; 95 \% \mathrm{CI}=1.08$ $16.75 ; \mathrm{P}=0.039)$ in the present study. Similarly, there was an association between older age and advanced stage (at diagnosis) of cervical cancer (OR:1.03, 95\% CI:1.01-1.05) in Sudan [50]. A study done in Florida also revealed that elderly women were more likely to be diagnosed at an advanced stage and each additional year of age was associated with 3\% increased odds of advanced cervical cancer diagnosis [55]. Previous researches in the USA have documented that older women are significantly less likely than younger women to undergo Pap testing [62-64] and therefore are more likely to present with advanced stage. In low middle-income countries, older women were also found to have long help-seeking intervals for their symptoms and were more likely to be diagnosed with advanced stage cervical cancer $[50,52,56,65]$. Older women also tend to believe that they are less vulnerable to cervical cancer and that Pap tests are not worthwhile [66]. This study also found that single women were more likely to be diagnosed as having advanced stage of cervical cancer compared with those who were married. This is consistent with studies carried out in Morocco which found that elevated risks for advanced stage was observed for unmarried women $(\mathrm{OR}=5.0$; 95\% CI:1.43-16.66) [38] and in Florida that revealed $63 \%$ increased odds among unmarried women to be diagnosed at advanced stage [55]. Married women might have better health habits and seek medical care sooner after the occurrence of 
symptoms of cervical cancer because of support and encouragement by their spouses $[57,67,68]$. Another reason could be that married women receive more frequent obstetric or gynaecological care, making them more responsive to reproductive health care [69] but it is assumed that unmarried women might not be currently sexually active and therefore less inclined to seek gynaecologic care. The risk of advanced cervical cancer at diagnosis was higher among HIV positive women compared to HIV negative women in this study. Kenya carries a large population infected with HIV, and limited prevalence of cervical cancer screening. Among all HIV positive women who were diagnosed with reproductive tract malignancies at Kenyatta National Hospital, 85\% had invasive cervical cancer [70]. This is mainly due to an association with immunosuppression resulting from HIV infection leading to rapidly invasive cancer progression from pre-invasive diseases [71,72]. A study from AIDS registries and cancer registries in 15 USA regions also found that persons with AIDS had statistically significantly elevated risk of invasive cervical cancer compared to the general population [73]. Due to the increased risk of developing cervical cancer for HIV positive women, it is recommended that HIV positive women in developed countries receive Pap smears annually, especially if they have low CD4 counts [74]. The Kenya national guidelines for antiretroviral therapy in 2011 require that cervical cancer screening and management be integrated within routine HIV care and treatment programs [75]. However, this is not practiced regularly in all health facilities. This study has revealed that high parity has increased proportion of advanced stage for diagnosis among women with cervical cancer in the bivariate analysis. However, this observation was not sustained at multivariate analysis. Upon considering both age and parity, the analysis revealed that parity was no longer significant but age maintained significant implying that parity was confounded by age.

\section{Study Limitation}

The major limitation of the study was selection bias since the study was carried out only at Kenyatta National Hospital; some women with high socio-economic status may prefer private health institution. The treatment and diagnosis procedure is much faster at private compared to Kenyatta National Hospital. The delay may be caused by referral systems in regional facilities to this national hospital since more than $70 \%$ are referred from other health facilities. There might also be a potential limitation on the grading of cervical cancer by the gynaecologist. However, it is done by at least two gynaecologists.

This study used data from medical records. As such, awareness of cervical cancer, socio-economic status, sexual characteristics and smoking or diet could not be explored other than the information in the records which was mostly incomplete. However, since this is the national and biggest public hospital with patients coming from all over the country, it provides a wide range of information about sociodemographic factors associated with advanced diagnosis of cervical cancer.

\section{Conclusion}

Women with cervical cancer had a higher probability of being diagnosed with advanced stage if they had a lower degree of education, old age, being single and HIV infection. These women should be targeted for regular cervical cancer screening. As one method of reducing the burden of advanced diagnosis of cervical cancer, health education programs and awareness campaigns to raise awareness among women about gynaecological symptoms should be provided. Cervical cancer screening and management of cervical cancer should be integrated with routine HIV care and treatment programs. Further research on the health system barriers for delayed cervical cancer is recommended.

\section{Declarations}

\section{Ethics approval and consent to participate}

This study was reviewed and approved by Kenyatta National Hospital/University of Nairobi Ethic and Research Committee (UP558/09/2014). This study used the secondary data without using individual's identification information, so there was no need of the informed consents from the study population. However, permission was requested and been granted from the record and cancer registry of the hospital.

\section{Consent to publish}

Each author has given final approval of the version to be published.

\section{Availability of data and materials}

The dataset used for analysis during the current study are available.

\section{Competing interests}

The authors declare that they have no competing interests.

\section{Funding}

This research was not funded by any organization as it was part of a course requirement.

\section{Authorship Contribution}

Kirema Makena Frida contributed in the design of the study, acquisition of data and in drafting manuscript. Wagoro Miriam Carole Atieno conceptualized the idea for the study, participated in its design, analysis, coordination and was involved in revising manuscript critically for important intellectual content. Michael Habtu involved in technical guidance in the design, performed statistical analysis and interpretation of data and helped to draft the manuscript.

\section{Acknowledgments}

The authors give special thanks to administrators and staff members of medical record at Kenyatta National Hospital for their cooperation and allowing us to conduct this research. We also acknowledge the Kenyatta National Hospital / University of Nairobi ethics and research committee for granting us authority to conduct this research.

\section{References}

1. Ferlay J, Shin HR, Bray F, Forman D, Mathers C, et al. (2008) Estimates of worldwide burden of cancer in 2008. Int J Cancer 127: 2893-2917.

2. Jemal A, Bray F, Center MM, Ferlay J, Ward E, et al. (2011) Global cancer statistics. CA Cancer J Clin 61: 69-90.

3. Devi BC, Tang TS, Corbex M (2007) Reducing by half the percentage of latestage presentation for breast and cervix cancer over 4 years: A pilot study of clinical down staging in Sarawak, Malaysia. Ann Oncol 18: 1172-1176.

4. h t t p s://extranet.who.int/iris/restricted / bitstream/10665/43942/1/9789241563710_eng.pdf

5. World Health Organization/Information Commissioner's Office (WHO/ICO) (2010) Information Centre on HPV and Cervical Cancer (HPV information centre): Human papillomavirus and related cancers in world. Summary Report, Geneva, Switzerland.

6. Bruni L, Barrionuevo-Rosas L, Albero G, Serrano B, Mena M, et al. (2016) ICO information centre on HPV and Cancer (HPV information centre). Human Papillomavirus and related diseases in Kenya. Summary Report.

7. Ministry of Public Health and Sanitation and Ministry of Medical Services (2012): National cervical cancer prevention program in Kenya: Strategic Plan 2012-2015. Nairobi, Kenya.

8. Pezzatini M, Marino G, Conte S, Catracchia V (2007) Oncology: A forgotten territory in Africa. Ann Oncol 18: 2046-2047.

9. Lomalisa P, Smith T, Guidozzi F (2000) Human immunodeficiency virus infection and invasive cervical cancer in South Africa. Gynecol Oncol 77: 460-463.

10. Rogo KO, Omany J, Onyango JN, Ojwang SB, Stendahl U (1990) Carcinoma of 
Citation: Frida KM, Atieno WMC, Habtu M (2017) Socio-Demographic Factors Associated with Advanced Stage of Cervical Cancer at Diagnosis in Kenyatta National Hospital, Kenya: A Cross Sectional StudyJ Cancer Sci Ther 9: 554-561. doi: 10.4172/1948-5956.1000473

the cervix in the African setting. Int J Gynaecol Obstet 33: 249-255.

11. Waggoner SE (2003) Cervical cancer. Lancet 361: 2217-2225.

12. Vinh-Hung V, Bourgain C, Vlastos G, Cserni G, De Ridder M, et al. (2007) Prognostic value of histopathology and trends in cervical cancer: a SEER population study. BMC Canc 7: 164-177.

13. Thomson C, Forman D (2009) Cancer survival in England and the influence of early diagnosis: What can we learn from recent EUROCARE results and quest. Br J Cancer 101: 102-109.

14. Briggs ND, Katchy KC (1990) Pattern of primary gynaecological malignancies as seen in a tertiary hospital situated in the River State of Nigeria. Int J Gynaeco Obstet 31: 157-161.

15. Sanghvi HC (1997) Cervical cancer screening in Kenya, In: Blumenthal PD (ed). Workshop Proceedings: Issues in cervical cancer-Seeking Alternatives to Cytology. JHPIEGO, pp. 14-19.

16. Ibfelt E, Kjaer SK, Johansen C, Hogdall C, Steding-Jessen M, et al. (2012) Socioeconomic position and stage of cervical cancer in Danish women diagnosed 2005 to 2009. Cancer Epidemiol Biomarkers Prev 21: 835-842.

17. Makin MS, Fort VK, Siegler AJ, Ault K, Rochat R (2011) Barriers to cervical cancer screening in Mulanje, Malawi: A qualitative study. Patient Prefer Adher 5: 125-131.

18. Bingham A, Bishop A, Coffey P, Winkler J, Bradley J, et al. (2003) Factors affecting utilization of cervical cancer prevention services in low resource settings. Salud Publica Mex 45: S408-S416.

19. Weiderpass E, Mutyaba T, Faxelid E, Mirembe F (2007) Influences on uptake of reproductive health services in Nsangi community of Uganda and their implications for cervical cancer screening. Reprod Heal 4.

20. Kawonga M, Fonn S (2008) Achievieng effective cervical cancer screening coverage in South Africa through human resources and health systems development. Reprod Health Matters 32: 32-40.

21. Murray SA, Grant E, Grant A, Kendall M (2003) Dying from cancer in developed and developing countries: Lessons from two qualitative interview studies of patients and their careers. Br Med J 326: 368-371.

22. Ngutu M, Nyamongo IK (2015) Exploring the barriers to health care and psychosocial challenges in cervical cancer management in Kenya. Int J Womens Health 7: 791-798.

23. World Health Organisation (2006) Comprehensive Cervical Cancer Control A guide to essential practice. In: Edited by Shapiro K, Ottolenghi E, Claeys $P$ Petitpierre J (eds) Geneva, Switzerland.

24. Ports KA, Reddy DM, Rameshbabu A (2015) Cervical cancer prevention in Malawi: A qualitative study of women's perspectives. J Health Commun 20: 97-104.

25. Gichangi P, Estambale B, Bwayo J, Rogo K, Ojwang S, et al. (2003) Knowledge and practice about cervical cancer and Pap smear testing among patients at Kenyatta National Hospital, Nairobi. Kenya Int J Gynecol Cancer 13: 827-833.

26. Morema EN, Atieli HE, Onyango RO, Omondi JH, Ouma C (2014) Determinants of cervical screening services uptake among 18 to 49 -year-old women seeking services at the Jaramogi Oginga Odinga teaching and referral hospital, Kisumu, Kenya. BMC Health Serv Rese 14: 335.

27. Were E, Nyaberi Z, Buziba N (2011) Perceptions of risk and barriers to cervical cancer screening at Moi Teaching and Referral Hospital (MTRH), Eldoret, Kenya. Afr Health Sci 11: 58-64.

28. Brown DR, Wilson RM, Boothe MA, Harris CE (2011) Cervical cancer screening among ethnically diverse black women: Knowledge, attitudes, beliefs, and practices. J Natl Med Assoc J Natl Med Assoc 103: 719-728.

29. Kivistic A, Lang K, Baili P, Anttila A, Veerus $P$ (2011) Women's knowledge about cervical cancer risk factors, screening, and reasons for non-participation in cervical cancer screening programme in Estonia. BMC Womens Health 11

30. Winkler J, Bingham A, Coffey P, Handwerker WP (2011) Women's participation in a cervical cancer screening program in northern Peru. Health Educ Res 23:10-24.

31. Coughlin SS, King J, Richards TB, Ekwueme DU (2006) Cervical cancer screening among women in metropolitan areas of the United States by individual-level and area-based measures of socioeconomic status, 2000 to 2002. Cancer Epidemiol Biomarkers Prev 15: 2154-2159.
32. Datta GD, Colditz GA, Kawachi I, Subramanian SV, Palmer JR, et al. (2006) Individual-, neighborhood-, and state-level socioeconomic predictors of cervical carcinoma screening among USA. black women: a multilevel analysis. Cancer 106: 664-669.

33. Ackerson K (2010) Personal influences that affect motivation in pap smear testing among African American women. J Obstetric Gynecologic Neonatal Nursing 39: 136-146.

34. Sankaranarayanan R, Thara S, Esmy PO, Basu P (2008) Cervical cancer: Screening and therapeutic perspectives. Med Princ Pract 17: 351-64

35. Gatune J, Nyamongo I (2005) An ethnographic study of cervical cancer among women in rural Kenya: Is there a folk causal model? Int J Gynecol Cancer 15:1049-1059

36. Cho H, Kim JH (2009) Treatment of the patients with abnormal cervical cytology: A "see-and-treat" vs. three-step strategy. J Gynecol Oncol 20: 164-168.

37. Brewer N, Pearce N, Jeffreys M, White P, Ellison-Loschmann L (2009) Demographic differences in stage at diagnosis and cervical cancer survival in New Zealand, 1994-2005. J Womens Health 18: 955-963.

38. Berraho M, Obtel M, Bendahhou K, Zidouh A, Errihani H, et al. (2012) Sociodemographic factors and delay in the diagnosis of cervical cancer in Morocco. Pan Afr Med J 12:14

39. Ibfelt E, Kjaer SK, Johansen C, Hogdall C, Steding-Jessen M, et al. (2012) Socioeconomic position and stage of cervical cancer in Danish women diagnosed 2005 to 2009. Cancer Epidemiol Biomarkers Prev 21: 835-842.

40. Fisher AA, Laing EJ, Stoeckel EJ, Townsend WJ (1998) Handbook for family planning operations research design. (2nd edn): Population Council, New York, NY, USA p. 36.

41. Knaub J (2008) Finite population correction (FPC) factor. In: Lavrakas P (ed) Encyclopedia of survey research methods. Đpp. 284-286. Thousand Oaks, CA SAGE Publications, Inc, NY, USA

42. Benedet JL, Bender H, Jones H, Ngan HY, Pecorelli S (2000) FIGO staging classifications and clinical practice guidelines in the management of gynecologic cancers. FIGO Committee on Gynecologic Oncology. Int J Gynaecol Obstet 70 : 209-262.

43. Ministry of Health: Review of the 2004-2008 reproductive health research agenda proposed 2010-2014 research agenda. Nairobi, Kenya

44. World Health Organization (2013) WHO guidelines for screening and treatment of precancerous lesions for cervical cancer prevention, Geneva, Switzerland.

45. Barillot I, Horiot JC, Pigneux J, Schraub S, Pourquier H, et al. (1997) Carcinoma of the intact uterine cervix treated with radiotherapy alone: A French cooperative study: Update and multivariate analysis of prognostic factors. Int J Radiat Oncol Biol Phys 38: 969-978.

46. Fyles AW, Pintilie M, Kirkbride P, Levin W, Manchul LA, et al. (1995) Prognostic factors in patients with cervix cancer treated by radiation therapy: Results of a multiple regression analysis. Radiother Oncol 35: 107-117.

47. Matovelo D, Magoma M, Rambau P, Massinde A, Masalu N (2012) HIV serostatus and tumor differentiation among patients with cervical cancer at Bugando Medical Centre. BMC Res Notes 5: 406.

48. Udigwe GO, Ogabido CA (2008) A clinico-pathological study of cervical carcinoma in South Eastern Nigeria: A five-year retrospective study. Niger J Clin Pract 11: 202-205.

49. Adewuyi SA, Shittu SO, Rafindadi AH (2008) Socio-demographic and clinicopathologic characterization of cervical cancers in northern Nigeria. E J Gynaecol Oncol 29: 61-64.

50. Ibrahim A, Rasch V, Pukkala E, Aro AR (2011) Predictors of cervical cancer being at an advanced stage at diagnosis in Sudan. Int J Womens Health 3: 385

51. Umezulike AC, Tabansi SN, Ewunonu HA, Nwana EJ (2007) Epidemiologica characteristics of carcinoma of the cervix in the Federal Capital Territory of Nigeria. Niger J Clin Pract 10: 143-146.

52. Gyenwali D, Khanal G, Paudel R, Khana G, Paudel R, et al. (2014) Estimates of delays in diagnosis of cervical cancer in Nepal. BMC Women's Health 14: 29

53. Behnamfar F, Azadehrah M (2015) Factors associated with delayed diagnosis of cervical cancer- A Survey in Isfahan City. Asian Pac J Cancer Prev 16: 635639. 
Citation: Frida KM, Atieno WMC, Habtu M (2017) Socio-Demographic Factors Associated with Advanced Stage of Cervical Cancer at Diagnosis in Kenyatta National Hospital, Kenya: A Cross Sectional StudyJ Cancer Sci Ther 9: 554-561. doi: 10.4172/1948-5956.1000473

54. Mlange R, Matovelo D, Rambau P, Kidenya B (2016) Patient and disease characteristics associated with late tumour stage at presentation of cervical cancer in Northwestern Tanzania. BMC Women's Health 25; 16.

55. Ferrante J, Gonzalez E, Roetzheim R, Pal N, Woodard L (2000) Clinical and demographic predictors of late-stage cervical cancer. Arch Fam Med 9: 439445

56. Kaku M, Mathew A, Rajan B (2008) Impact of socio-economic factors in delayed reporting and late-stage presentation among patients with cervix cancer in a major cancer hospital in South India. Asian Pac J Cancer Prev 9: 589-594.

57. Nene B, Jayant K, Arrossi S, Shastri S, Budukh A, et al. (2007) Determinants of women's participation in cervical cancer screening trial, Maharashtra, India. Bull World Health Organ 85: 264-272

58. Bradley J, Risi L, Denny L (2004) Widening the cervical cancer screening net in a South African township: Who are the underserved? Health Care Women Int 25: 227-241.

59. Franceschi S, Plummer M, Clifford G, De Sanjose S, Bosch X, et al. (2009) Differences in the risk of cervical cancer and human papillomavirus infection by education level. Brit J Cancer 101: 865-870.

60. Galobardes B, Shaw M, Lawlor DA, Lynch JW, Davey SG (2006) Indicators of socioeconomic position (part 2). J Epidemiol Community Health 60: 95-101.

61. Lourenco AV, Fregnani CM, Silva PC, Latorre MR, Fregnani JH (2012) Why are women with cervical cancer not being diagnosed in preinvasive phase? An analysis of risk factors using a hierarchical model. Int J Gynecol Cancer 22: 645-653.

62. Potosky AL, Breen N, Graubard BI, Parsons PE (1998) The association between health care coverage and the use of cancer screening tests. Results from the 1992 National Health Interview Survey. Med Care 36: 257-270.

63. Sawaya GF, Sung HY, Kearney KA, Miller M, Kinney W, et al. (2001) Advancing age and cervical cancer screening and prognosis. J Am Geriatr Soc 49:14991504.

64. Wells BL, Horm JW (1998) Targeting the underserved for breast and cervical cancer screening: The utility of ecological analysis using the National Health Interview Survey. Am J Public Health 88:1484-1489.
65. Anorlu RI, Orakwue CO, Oyeneyin L (2004) Late presentation of patients with cervical cancer to a tertiary hospital in Lagos: What is responsible? Eur $J$ Gynaecol Oncol 25: 729-732.

66. Lerman C, Caputo C, Brody D (1990) Factors associated with inadequate cervical cancer screening among lower income primary care patients. J Am Board Fam Pract 3:151-156.

67. Lyimo FS, Beran TN (2014) Demographic, knowledge, attitudinal, and accessibility factors associated with uptake of cervical cancer screening among women in a rural district of Tanzania: Three public policy implications. BMC Public Health 12: 22

68. Gan DE, Dahlui M (2013) Cervical screening uptake and its predictors among rural women in Malaysia. Singapore Med J 4:163-8.

69. Siahpush M, Singh GK (2002) Sociodemographic predictors of pap test receipt currency and knowledge among Australian women. Prev Med 35:362-368

70. Gichangi P, De Vuyst H, Estambale B, Rogo K, Bwayo J, et al. (2002) HIV and cervical cancer in Kenya. Int J Gynaecol Obstet 76: 55-63.

71. Moscicki AB, Ellenberg JH, Vermund SH, Holland CA, Darragh T, et al. (2000) Prevalence of and risks for cervical human papillomavirus infection and squamous intraepithelial lesions in adolescent girls: Impact of infection with human immunodeficiency virus. Arch Pediatr Adolesc Med 154: 127-134.

72. Strickler HD, Burk RD, Fazzari M, Anastos K, Minkoff H, et al. (2005) Natura history and possible reaction of human papillomavirus in HIV positive women. J Natl Cancer Inst 97: 577-586.

73. Chaturvedi AK, Madeleine MM, Biggar RJ, Engels EA (2009) Risk of human papillomavirus-associated cancers among persons with AIDS. J Natl Cancer Inst 101:1120-1130.

74. Bardaro L (1996) Cervical cancer screening issues for HIV-positive women. BETA 35-38.

75. Ministry of Health, National AIDS and STI Control Programme (2016) Guidelines on use of Antiretroviral drugs for treating and preventing HIV Infection in Kenya 2016. Nairobi, Kenya: NASCOP. 